\title{
Entropy of Global Financial Linkages
}

\author{
Daeyup Lee*
}

The views expressed herein are those of the author and do not necessarily re-

flect the offcial views of the Bank of Korea. When reporting or citing this paper, the author's name should always be stated explicitly.

* International Economics Team, Institute for Economic Research, The Bank of Korea, Email: dylee484@bok.or.kr

The author is grateful to Woon Gyu Choi, Hyun-Jeong Kim, Geun-Young Kim, Junhan Kim, Ki-Ho Kim, Tae-Su Kang, and seminar participants at the Bank of Korea for their useful comments and suggestions. 


\section{Contents}

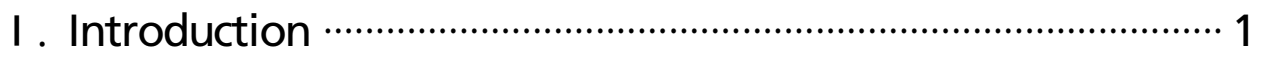

II. Data and Methodology …………………………………… 4

2.1 Data

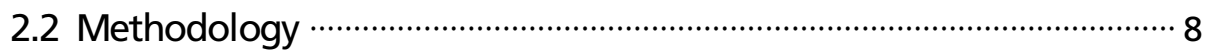

2.2.1 Transformation of Adjacency Matrices into Stochastic Matrices $\cdots 8$

2.2.2 Network Entropy ……………………………………………….... 10

III. Network Entropy of Global Financial Networks …............ 13

3.1 Core (reporting countries) ………………………………………...... 13

3.1.1 Network Entropy: An Indicator for Global Financial Networks * 13

3.1.2 Network Entropy and SIFls ……………………............................ 19

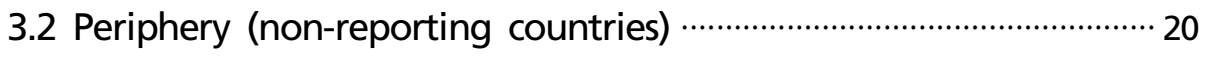

3.2.1 Counterparty Entropy ………………………………………………. 20

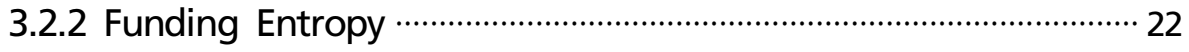

3.2.3 Funding Entropy and Volatility …………………………………... 23

3.2.4 Funding Entropy and Financial Linkages ………………………... 24

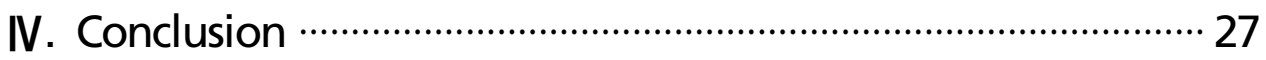

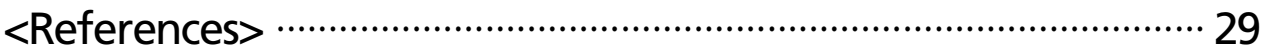




\section{Entropy of Global Financial Linkages}

This paper proposes network entropy as a tool for measuring diversity of highly connected financial networks. The computation of network entropy hinges on eigenvector centrality and Shannon entropy.

Two policy-related findings emerge from this research. First, regarding time variation of network entropy, international diversification of the global financial network constructed from foreign claims of international banks has retreated since the financial crisis of 2007-2008. Foreign claims among 20 reporting countries have become more concentrated on core countries such as US and UK since 2009. The change is more vividly captured by network entropy with an unprecedented drop of the measure. This finding illustrates that network entropy is a more acute measure for diversity of a financial network due to the inclusion of information about financial network structures captured by eigenvector centrality.

Second, on the subject of financial linkages, the results reveal sizable regional heterogeneity. In both developing Asia \&.Pacific area and developing Africa \& Middle East area, there is a negative correlation between volatility of changes in foreign claims and international diversification of funding sources measured by funding entropy. In other words, more international diversification is related with lower volatility. Especially in case of developing Europe, however there is no evidence for the relation. This paper also finds interesting regional variations in the relation between international diversification of lending and that of borrowing.

Keywords: Network Entropy, Funding Entropy, Global Financial Networks, International Diversification

JEL Classification: F3, F6 


\section{I . Introduction}

The recent financial crises from 2007 highlight the importance of interconnected global financial markets in the global economy (Yellen, 2013). Research on global financial networks from the viewpoint of financial stability has become popular (BIS, 2010; IMF, 2010). Moreover, global financial networks are naturally related with another important topic, global liquidity. For example, Shin (2012) emphasizes the role of global banks in transmission of global liquidity across borders. In this context, it is important to develop quantitative methods for analyzing financial networks. The current literature on financial networks mainly focuses on the connectivity of networks via the number of links. The network structure of international financial markets has become close to complete graphs with the the advancement of international financial integration. Therefore, it seems that we need finer tools for analyzing highly connected networks.

From a primarily descriptive perspective, this paper aims to contribute to understanding the network structure of global financial markets by providing a network entropy measure of network diversity (or international diversification) proposed by Demetrius and Manke (2005). The measure is readily applicable to highly connected networks.

Roughly speaking, network entropy is composed of two elements: eigenvector centrality and (Shannon) entropy. Eigenvector centrality which in general depends on network structures is one of the measures of node centrality in network analysis. Several recent papers advocate the usefulness of eigenvector centrality in the analysis of financial networks (Bech et al., 2010; Markose, 2012; Markose et al., 2012; Cetorelli and Peristiani, 2013). In turn, entropy has been used as a measure of diversification in the economic literature. For example, Jacquemin and Berry (1979) develop an entropy measure of corporate diversification. ${ }^{1)}$ To the best of my knowledge, however entropy measures have been rarely employed for the analysis of financial networks. ${ }^{2}$ In the context of the analysis of financial networks, entropy can be viewed as a measure of the diversification of the links of a node in a network. By

1) For a review of applications of entropy in finance, see Zhou et al. (2013).

2) Recently, Peron et al. (2012) apply the concept of network entropy to stock correlation networks. 
combining eigenvector centrality and entropy, we obtain entropy of a node. The entropies of nodes can reveal heterogeneity of nodes even if they are completely connected. Finally, network entropy is a weighted sum of the entropies of nodes in a network. Therefore network entropy is a network-wide measure of diversification taking into account network structures by incorporating eigenvector centrality.

In this paper, I apply the measure of network entropy to the BIS global financial network database in order to study highly connected global financial networks. Based on the new measure of network diversity, the research questions in this paper are two-fold: First, how has the network structure of global banking networks among core countries (i.e., reporting countries) evolved during the global financial crisis of 2007-2009 in terms of diversification? Second, how are core countries and periphery countries (i.e., non-reporting countries) interconnected in terms of financial linkages?

The literature on financial networks has been growing rapidly.3) Empirical works can be divided into two strands: one strand focuses on data-based investigation of financial networks to grasp their features. For example, Weistroffer and Möbert (2010) utilize the BIS consolidated banking sector statistics to investigate cross-border exposure. They provide several vulnerability measures. Among them, the "borrower concentration ratio" which is based on the Herfindahl Index, is similar to entropy in the sense that two measures gauge the extent of diversification of lending. A higher "borrower concentration ratio" may be interpreted as higher contagion risk. Minoiu and Reyes (2013) look at the BIS locational statistics focusing on flows rather than exposures. By employing network metrics, they find that connectivity tends to decline during and after financial crises. Hale (2012) builds a bank-level global financial network and finds out the systematic effect of recessions and banking crises on the global banking network. Castrén and Rancan (2013) extend cross-border network of the banking sectors in the Euro area to include sector networks of each country and highlight the tradeoff between efficiency and stability

3) The pioneering work by Allen and Gale (2000) finds that complete connection is more robust to financial contagion. Recently, Acemoglu et al. (2013) claim that the conclusion depends on the size and number of negative shocks. Caballero and Simsek (2013) argue that in bad times, perceived counterparty risk increases because of higher uncertainty regarding relevant financial networks. 
in financial networks.

Several papers, like this paper, utilize eigenvector centrality in analyzing networks. On the one hand, Bech et al. (2010) use the dominant left eigenvector of a (modified) weighted adjacency matrix to rank participants in the Canadian Large Value Transfer System with respect to their daily liquidity holdings. Cetorelli and Peristiani (2013) also utilize the dominant left eigenvector of a matrix of IPO flows to assess the importance of international financial centers in attracting global IPOs. On the other hand, Markose (2012) and Markose et al. (2012) study financial derivatives from the perspective of network analysis and propose a super-spreader tax based on the dominant right eigenvector. Based on these papers, my paper goes further by applying an entropy measure based on eigenvector centrality.

The research of the other strand centers around the question of how the financial networks transmit exogenous shocks to financial markets. Network simulation techniques have been widely used for this research.4)

Two policy-related findings emerge from this research. First, regarding the time variation of network entropy, the international diversification of the global financial network constructed from foreign claims of international banks retreats after the financial crisis of 2007-2008. Foreign claims among 20 reporting countries have become more concentrated on core countries such as the US and the UK from 2009. The change is more vividly captured by network entropy with an unprecedented drop in the measure.5) This finding demonstrates that network entropy is a more sensitive measure for the diversity of a financial network due to the inclusion of information about financial network structures captured by eigenvector centrality.

Second, on the subject of financial linkages, the results reveal sizable regional heterogeneity. In both developing Asia \&Pacific area and developing Africa \&

4) For instance, Degryse et al. (2010) study cross-border contagion risk over the period 1999-2006 by using cross-border exposures data of 17 countries from BIS Banking Statistics. They adopt the approach developed in Upper and Worms (2004) and find that contagion risk climbed during the period. Gai et al. (2011) derive a tipping point condition of contagion dynamics in financial networks. Their simulation experiments reveal that concentration and complexity of financial networks can be important amplifiers of financial fragility. For an up-to-date survey, see Upper (2011).

5) Higher network entropy represents more diverse paths from each node. So the networks with higher network entropy are more robust to random perturbations. This implication is in line with Allen and Gale (2000) where they find that a complete network is more resilient than an incomplete network. 
Middle East area, there is a negative correlation between volatility of changes in foreign claims and international diversification of funding sources measured by funding entropy. In other words, more international diversification is related with lower volatility. Especially in case of developing Europe, however, there is no evidence for such a relation. This paper also finds interesting regional variations regarding the relation between international diversification of lending and that of borrowing.

The paper is organized as follows. Section 2 presents the data and the methodology used in this paper. Section 3 reports the main results of the paper. Section 4 concludes.

\section{Data and Methodology}

\subsection{Data}

I use the BIS consolidated banking statistics. The main advantage of the statistics compared with BIS locational statistics is the fact that the statistics provide information on exposures by country of immediate borrower and on the country of ultimate risk (BIS, 2012). Figure 1 illustrates the distinctive coverage of three types of claims reported in the statistics. This paper focuses mainly on the foreign claims, the most extensive measure. But I will also look at international claims for the robustness of analysis.

The remaining part of this subsection provides the recent trends of some aggregate variables from BIS consolidated banking statistics. Figure 2 shows that the global network of foreign claims has been significantly impeded, after reaching a peak in 2008 Q1. The left panel displays foreign claims on immediate borrower basis. International claims are also shown in the panel for comparison. The right panel draws foreign claims on an ultimate risk basis together with cross-border claims for comparison.6)

6) Claims on an immediate borrower basis include all items representing an on-balance sheet financial asset except on-balance sheet derivatives instruments with a positive market value. Country of ultimate risk is the country where the ultimate obligor resides (BIS, 2012). 
Figure 1: Types of Claims

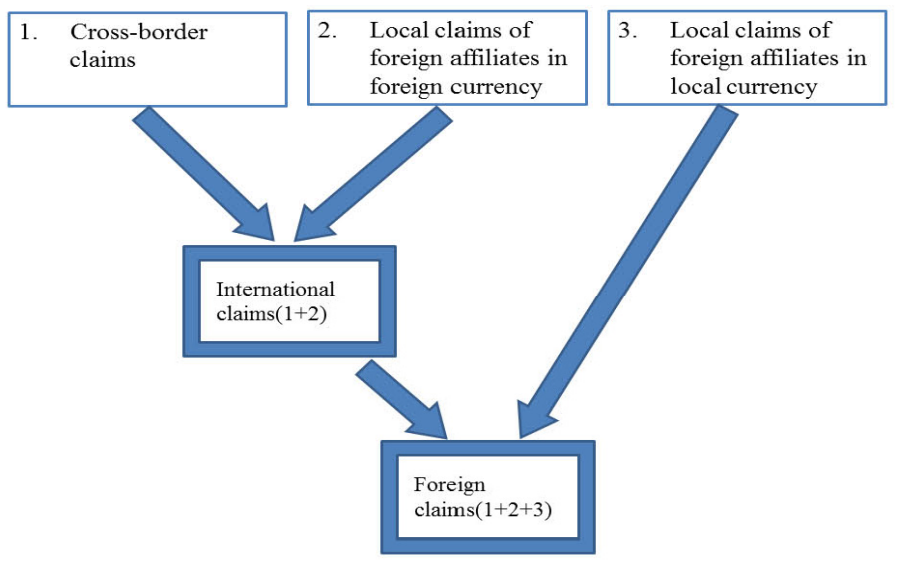

Source: BIS (2012).

Figure 2: Trends of Aggregate Variables
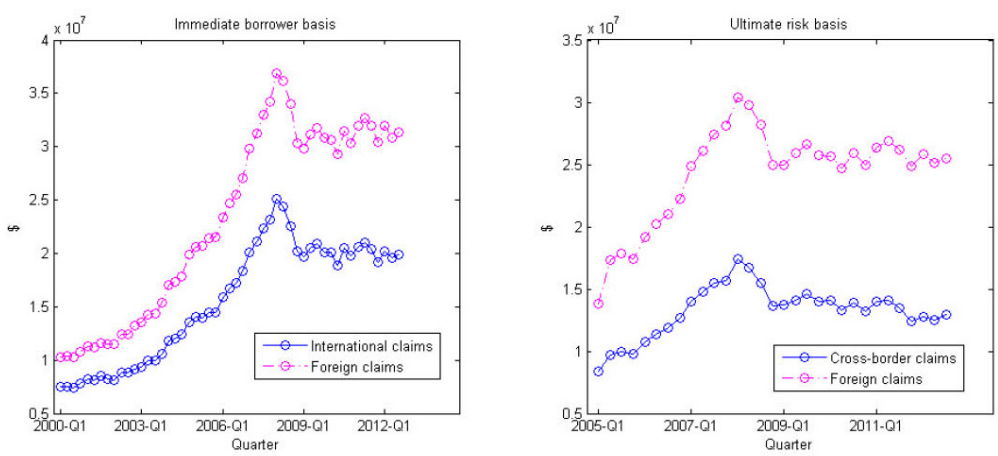

Source: BIS Consolidated Banking Statistics.

Figure 3: Sectoral Claims
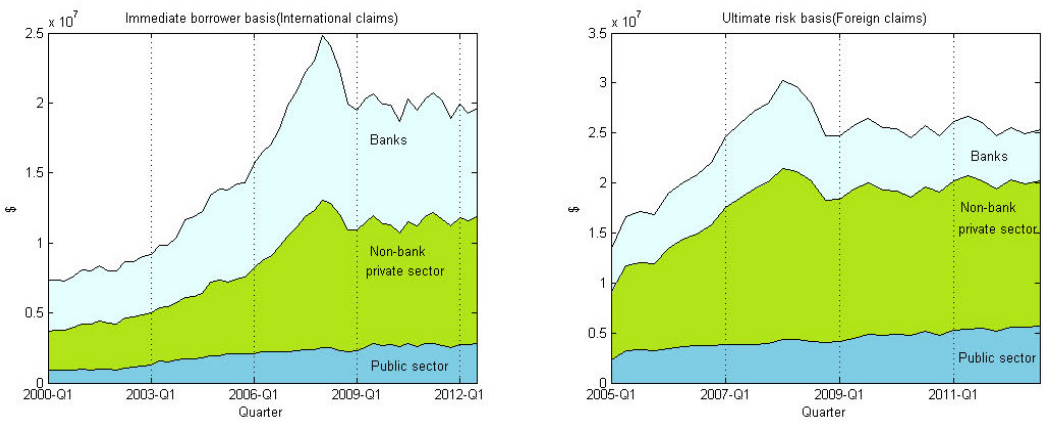

Source: BIS Consolidated Banking Statistics. 
Figure 3 provides sectoral decomposition of foreign claims. We can see that foreign claims on banking sector are most significantly retreated during the recent turmoil in international financial markets whereas foreign claims on the public sector have been steadily growing. Again, the left panel displays the foreign claims on an immediate borrower basis and the right panel charts the foreign claims on an ultimate risk basis.

Among reporting countries, 20 countries are chosen because of data availability. Figure 4 depicts the trends of foreign claims of the 20 countries. Likewise, Figure 4 shows separately the foreign claims on an immediate borrower basis and the foreign claims on an ultimate risk basis. Figure 4 reveals that the subnetwork of 20 reporting countries has stagnated more severely than the whole network. But Figure 4 does not give us the information about whether there are changes in the structure of international financial markets. To answer the question, it may be helpful to look at the network properties of the markets.

Figure 4: Total Foreign Claims (2006 Q1 -2012 Q3)
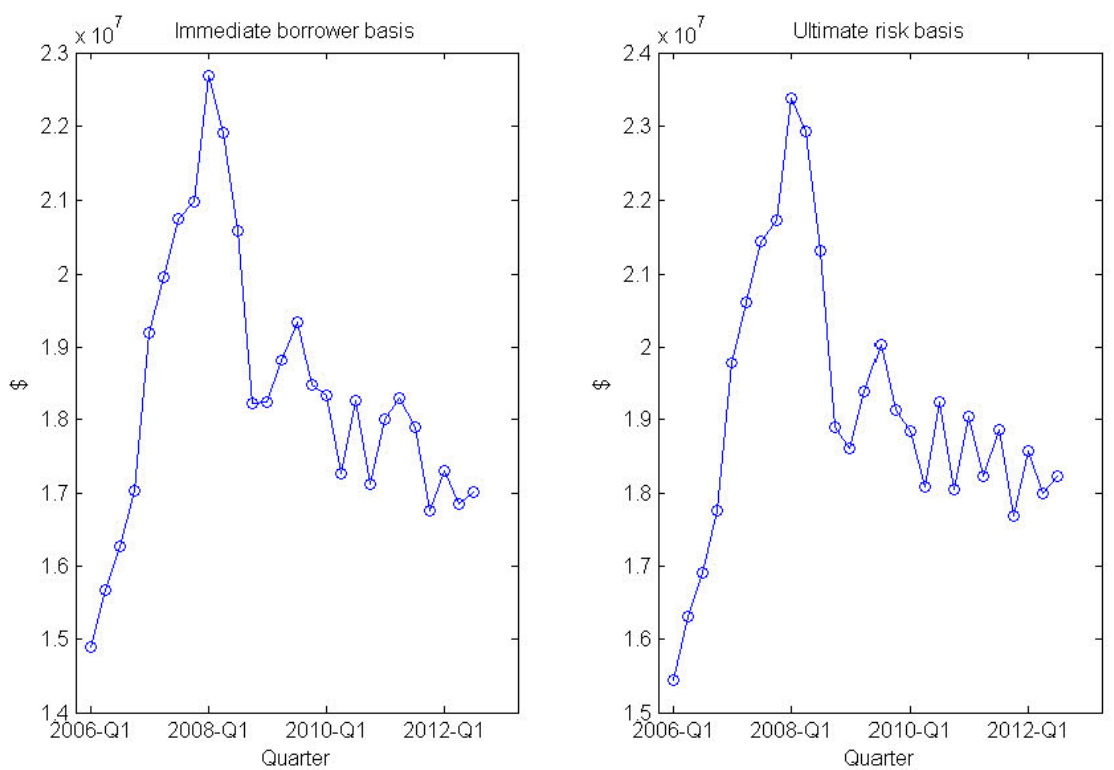

Note: The following is a list of the 20 countries: Austria, Australia, Belgium, Canada, Chile, France, Germany, Greece, India, Ireland, Italy, Japan, Netherlands, Portugal, Spain, Sweden, Switzerland, Turkey, United Kingdom, United States

Source: BIS Consolidated Banking Statistics. 
Figure 5: 2006 Q1

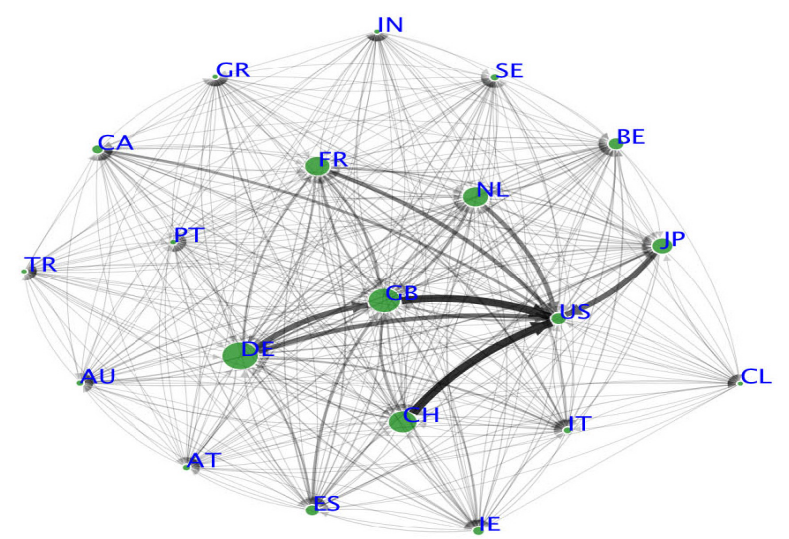

Note: AT:Austria, AU:Australia, BE:Belgium, CA:Canada, CH:Switzerland, CL:Chile, DE:Germany, ES:Spain, FR:France, GB:United Kingdom, GR:Greece, IE:Ireland, IN:India, IT:Italy, JP:Japan, NL:Netherlands, PT:Portugal, SE:Sweden, TR:Turkey, US:United States Source: BIS Consolidated Banking Statistics (ultimate risk basis)

Figure 6: 2012 Q3

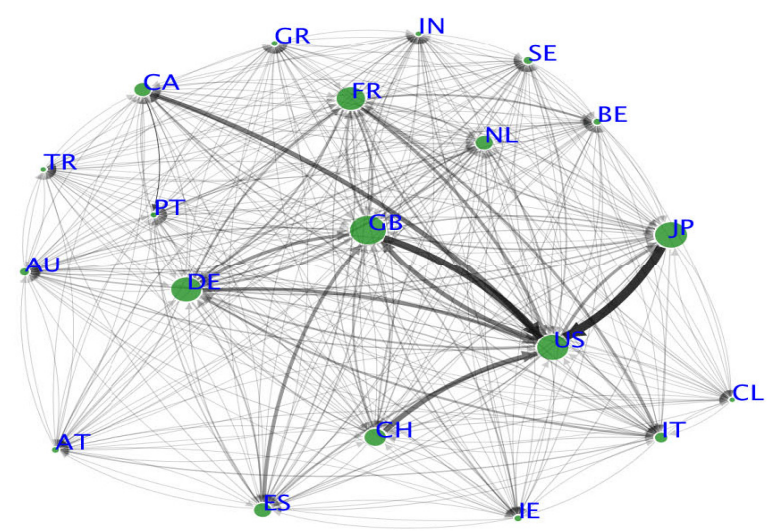

Source: BIS Consolidated Banking Statistics (ultimate risk basis).

Figures 5 and 6 represent global financial networks constructed based on foreign claims among 20 reporting countries 7 ). The size of the nodes is proportional to the amount of lending made by a country. And the thickness of the link lines is

7) For visualization of financial networks, I use the software, financial network analytics (FNA), developed by Kimmo Soramäki which is available at www.fna.fi. 
determined by the fraction of the foreign claims of one country upon another country in its total foreign claims. We can see from the figures that there have been changes in relative shares of the volumes of lending made by the countries. For instance, the nodes of the US and Japan are bigger in 2012 than in 2006. To see the changes more precisely, we need some quantitative measures for networks. As a quantitative measure of networks, I introduce the concept of network entropy and related tools in subsection 2.2 .

\subsection{Methodology}

A network $(\mathrm{N}, \mathrm{A})$ is defined by a set of nodes $\mathrm{N}=\{1,2, \cdots, n\}$ and an adjacency matrix $A=\left(a_{i j}\right)_{1 \leq i, j \leq n}{ }^{8}$ ) A node (or vertex) is the basic items of the network. Nodes can be individuals, groups, or other things such as cities and web pages. In this paper, a node represents a country in global financial markets. Nodes are connected by edges (or links). An edge score $a_{i, j}$ of the adjacency matrix A corresponds to (strength of ) interaction between node $\mathrm{i}$ and node $\mathrm{j}$. In general, the edge score $a_{i, j}$ can take either binary values (unweighted network) or real values (weighted network). If $a_{i, j} \neq a_{i, j}$ for some pair $(\mathrm{i}, \mathrm{j})$, then the corresponding network is called directed. Otherwise, it is called undirected. In this paper, $a_{i, j}$ represents foreign claims of country $\mathrm{i}$ on country $\mathrm{j}$, which implies that the network is a weighted and directed network. Moreover, since foreign claims have nonnegative values, the adjacency matrix $\mathrm{A}$ is a nonnegative matrix.9) If a financial network is $a$ complete network, then the adjacency matrix $\mathrm{A}$ is also primitive.10)

\subsubsection{Transformation of Adjacency Matrices into Stochastic Matrices}

We need to transform adjacency matrices into stochastic matrices to apply the concept of (Shannon) entropy. In this paper, I adopt the method proposed by Demetrius and Manke (2005). Before introducing the method, I first consider a more straightforward normalization, i,e., a fraction of total foreign claims for comparison.

8) For general introduction to network theory, see Jackson (2008) and Newman (2011) for examples.

9) Each element $a_{i, j}$ of the adjacency matrix A takes a nonnegative real value.

10) If there exists positive integer $\mathrm{k}$ such that $A^{k}>0$ for nonnegative square matrix $\mathrm{A}$, then the matrix $\mathrm{A}$ is called primitive (Seneta, 2006). 
Method 1 Given an adjacency matrix A, a stochastic matrix $\hat{P}=\left(\hat{p}_{i j}\right)$ can be defined as follows:

$$
\hat{p}_{i j}=\frac{a_{i j}}{\sum_{j} a_{i j}}
$$

'Method 1' treats each node uniformly. In other words, 'Method 1' does not take into account possible heterogeneity of nodes. 'Method 1' will serve as a benchmark.

Method 2 In the literature on networks, several measures of centrality have been developed.11) Among them, the eigenvector centrality proposed by Bonacich (1972) is based on neighbors' characteristics. The basic idea of eigenvector centrality is that a node's centrality depends on the centralities of its neighbors. In particular, Bonacich (1972) assumes that a node's centrality is proportional to weighted sum of edge scores where weights are provided by centrality scores. Given an adjacency matrix A, the assumption yields a system of homogenous linear equations for the unknown variables, centrality scores $v:=\left\{v_{1}, v_{2}, \cdots, v_{n}\right\}$, as in Bonacich (1972):

$$
\sum_{j} a_{i j} v_{j}=\lambda v_{i}, 1 \leq i, j \leq n
$$

where $\lambda$ is a proportionality constant. The centrality scores should be non-negative. Equation (2) illustrates why the proposed centrality is called the eigenvector centrality. The pair $(\lambda, v)$ corresponds to an eigenvalueeigenvector pair of the adjacency matrix $\mathrm{A}$.

Suppose that an adjacency matrix $\mathrm{A}$ is a nonnegative and primitive matrix. Then, the famous Perron-Frobenius theorem (Seneta, 2006, Theorem 1.1) tells us that there exists a dominant eigenvalue-eigenvector pair, $\left(\lambda_{\max }, v_{\max }\right)$ such that

$$
A v_{\max }=\lambda_{\max } v_{\max }
$$

where both $\lambda_{\max }$ and $v_{\max }$ are positive. ${ }^{12)}$ I normalize vmax so that $\Sigma_{j} v_{\max }(j)=1$. $v_{\max }(j)$ can be described as a measure of relative contribution made by node $\mathrm{j}$ to the

11) See Jackson (2008, 2.2.4) and Newman (2011, ch.7).

12) See also Lax (2008) for the proof of Perron theorem for positive matrices. 
network. In global financial networks, the right eigenvector $v_{\max }(j)$ represents relative contribution made by country $\mathrm{j}$ to lending money. Then, given an adjacency matrix A, 'Method 2' defines a stochastic matrix $P^{*}=\left(p_{i j}^{*}\right)$ as follows:

$$
\mathrm{p}=\frac{a_{i j} v_{\max }(j)}{\lambda_{\max } v_{\max }(i)}, 1 \leq i, j \leq n
$$

So, the components of row $\mathrm{i}$ of A are weighted by $\left(v_{\max }(j)\right)_{1 \leq j \leq n}$ and normalized by multiplying them by $\frac{1}{\lambda_{\max } v_{\max }(i)}$.

The (scaled) power method for computing dominant eigenvector gives us another useful implication for eigenvector centrality. ${ }^{13)}$ Let a nonnegative vector $b_{0}$ be given. According to the power method, the sequence, $b_{i+1}=\frac{A b_{i}}{\left\|A b_{i}\right\|}$, will converge to the dominant eigenvector. The method utilizes the fact that the direction of $A^{i} b_{0}$ converges to the direction of the eigenvector regardless of the initial point, $b_{0}$ (Meyer, 2000). The result implies that the weights of nodes determined by the dominant eigenvector reflects asymptotic effect of initial perturbations on network. Or, as Bonacich (2007) points out, the eigenvector centrality takes into account not only direct links but also indirect links. In this regard, the eigenvector centrality may be a valuable tool for analyzing network structures.

\subsubsection{Network Entropy}

Several entropy measures have been used as a complexity measure of a graph (Dehmer and Mowshowitz, 2011). Following Demetrius and Manke (2005), I apply the well-known Shanonn entropy formula (Shannon, 1948). Given a discrete probability distribution $D=\left\{p_{1}, p_{2}, \cdots, p_{n}\right\}$, the formula is defined as follows: ${ }^{14)}$

$$
H(D)=-\sum_{i=1}^{n} p_{i} \log p_{i}
$$

13) A similar convergent result for the power method is discussed in Bonacich (1972).

14) Shannon (1948) takes an axiomatic approach to derive the formula. Shanonn entropy is the unique measure satisfying the following three requirements:

1. The entropy should be a continuous function of the $p_{i}$

2. If the distribution is uniform, then the entropy should be a monotonic increasing function of $n$.

3. If a choice be split into two successive choices, then the original entropy should be the weighted sum of the entropies of the two successive choices. 
Note that $\mathrm{H}$ (D) can be viewed as the expected value of the random variable $\left.\log \left(\frac{1}{p}\right) .15\right)$ In particular, from the viewpoint of financial network analysis, entropy can be described as a measure of diversification due to the fact that the formula makes a more evenly distributed random variable obtain higher entropy.

Given a stochastic matrix $\left(\mathrm{P}=\left(p_{i j}\right)\right)$ derived from an adjacency matrix of a network, the entropy $\left(H_{i}\right)$ of a node $\mathrm{i}$ is obtained by applying the formula to transition probability distribution which corresponds to the ith row of the stochastic matrix $(\mathrm{P})$.

$$
H_{i}(P)=-\sum_{i=1}^{n} p_{i j} \log p_{i j}, 1 \leq i \leq n
$$

$H_{i}(P)$ measures the diversity of choices of the node i. Then, the network entropy $\left(H_{\text {network }}\right)$ is defined as the weighted sum of entropies of nodes.

$$
H_{\text {network }}(P)=\sum_{i=1}^{n} \pi_{i} H_{i}
$$

where the weighting vector $\pi=\left\{\pi_{1}, \pi_{2}, \cdots, \pi_{n}\right\}$ is the unique invariant distribution of the corresponding stochastic matrix $(\mathrm{P})$.

$$
\pi P=\pi
$$

If a stochastic matrix is ergodic (or primitive), the unique invariant distribution is well-defined (Koralov and Sinai, 2012, Theorem 5.9). ${ }^{16)}$ The left eigenvector $\pi$ is a measure of relative contributions made by countries in borrowing money from global financial markets. Summing up, the computation algorithm for network entropy is as follows:

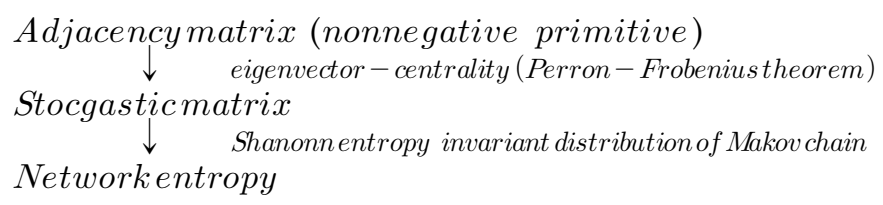

15) In this context, one interpretation of $\log \left(\frac{1}{p_{i}}\right)$ is "the amount of surprise" when we observe event $i$.

16) A stochastic matrix is called ergodic if there exists $n \in \mathbb{N}$ such that $p_{i j}^{(n)}>0, \forall i, j$ where $p_{i j}^{(n)}$ represents the n-step transition probabilities of a Markov chain. 
In general, $H_{\text {network }}(P)$ quantifies the average diversity of choices of nodes. Particularly, in this paper, $H_{\text {network }}(P)$ is a measure of international diversification in global financial networks.

To grasp the difference between two methods, I go over the simple example illustrated by Figure 7. The simple example compares two different networks of three countries, a, b, and c. Note that the adjacency matrices

$$
A_{\alpha}=\left[\begin{array}{lll}
0 & 1 & 2 \\
2 & 0 & 1 \\
1 & 2 & 0
\end{array}\right], A_{\beta}=\left[\begin{array}{lll}
0 & 1 & 5 \\
2 & 0 & 1 \\
1 & 2 & 0
\end{array}\right]
$$

In case $\alpha$, the situation is symmetric to each country. Each country has the same international asset allocation. So, as we can see from Table 1, two methods give us the same results.

In case $\beta$, the symmetry breaks because country 'a' holds more foreign assets in country 'c' than in case $\alpha$. Now, two methods yield different results. For method 1 , the entropies of countries b and c are the same as before. Only the entropy of country 'a' decreases because of the higher concentration of foreign asset holdings. Network entropy also goes down reflecting the drop of the entropy of country 'a'. In comparison with method 1 , the computation of entropy by method 2 is more involved because of the additional component, eigenvector centrality $\left(v_{i}\right)$. The expansion of foreign asset holdings by country ' $a$ ' increases the eigenvector centrality of country ' $a$ '. The expansion also has indirect effect on country 'b'. Country 'b' invests more in country 'a' than country 'c' does. So, the eigenvector centrality of country 'b' also mounts. Note that the node entropies of three countries all change even though only the asset allocation of country 'a' has changed. And the resulting network entropy is a little bit lower than the network entropy obtained from method 1.

\section{Table 1: A Simple Example}

\begin{tabular}{|c|c|c|c|c|c|c|c|c|c|c|c|c|c|c|}
\hline & \multicolumn{6}{|c|}{ method 1} & \multicolumn{8}{|c|}{ method 2} \\
\hline & \multicolumn{2}{|c|}{$\left(H_{i}\right)$} & \multicolumn{2}{|c|}{$\left(\pi_{i}\right)$} & \multicolumn{2}{|c|}{$\left(H_{n e t w o r k}\right)$} & \multicolumn{2}{|c|}{$\left(v_{i}\right)$} & \multicolumn{2}{|c|}{$\left(H_{i}\right)$} & \multicolumn{2}{|c|}{$\left(\pi_{i}\right)$} & \multicolumn{2}{|c|}{$\left(v_{i}\right)$} \\
\hline & $\alpha$ & $\beta$ & $\alpha$ & $\beta$ & $\alpha$ & $\beta$ & $\alpha$ & $\beta$ & $\alpha$ & $\beta$ & $\alpha$ & $\beta$ & $\alpha$ & $\beta$ \\
\hline a & 0.64 & 0.45 & 0.33 & 0.33 & \multirow{3}{*}{0.64} & \multirow{3}{*}{0.58} & 0.33 & 0.43 & 0.64 & 0.47 & 0.33 & 0.36 & \multirow{3}{*}{0.64} & \multirow{3}{*}{0.57} \\
\hline$b$ & 0.64 & 0.64 & 0.33 & 0.30 & & & 0.33 & 0.30 & 0.64 & 0.55 & 0.33 & 0.28 & & \\
\hline c & 0.64 & 0.64 & 0.33 & 0.37 & & & 0.33 & 0.27 & 0.64 & 0.68 & 0.33 & 0.36 & & \\
\hline
\end{tabular}

Note: The table illustrates the difference between the two methods. 
Figure 7: An Example

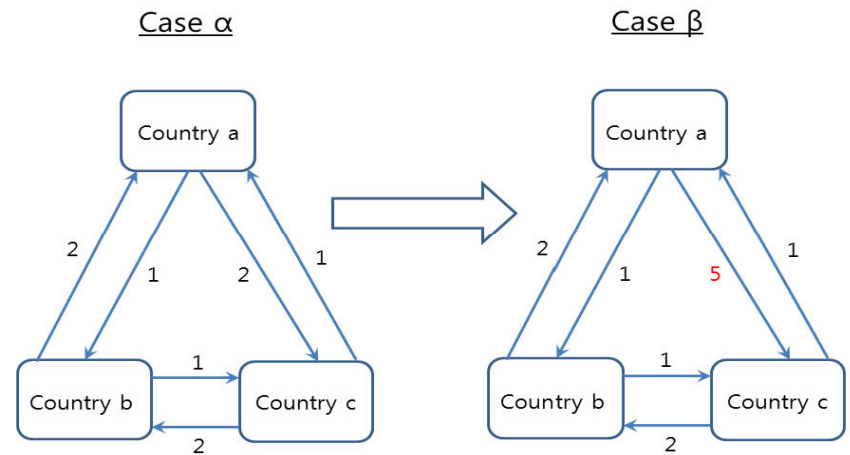

\section{Network Entropy of Global Financial Networks}

\subsection{Core (reporting countries)}

\subsubsection{Network Entropy: An Indicator for Global Financial Networks}

The sample period of foreign claims is from the first quarter of 2006 to the third quarter of 2012 (Q1, 2006 - Q3, 2012). Figures 8 and 9 depict the networks associated with the stochastic matrices which are constructed from foreign claims of twenty countries. Hence, the figures provide the snapshots of global financial networks in 2006 Q1 and 2012 Q3 from the viewpoint of a network entropy approach. The width of each edge in the networks is proportional to the components of the stochastic matrices and the size of each node is determined by the invariant distributions for the stochastic matrices. Compared with Figures 5 and 6 , Figures 8 and 9 reveal the crucial roles played by leading countries in incorporating the heterogeneity of nodes in terms of eigenvector centrality. Other countries lend disproportionately large amounts of money to leading countries. In turn, the comparison between Figures 8 and 9 uncovers a notable shrinkage of Germany's weight and a sizable increase in the weight of the US in global financial networks. 
Figure 8: Foreign Claims (2006 Q1)

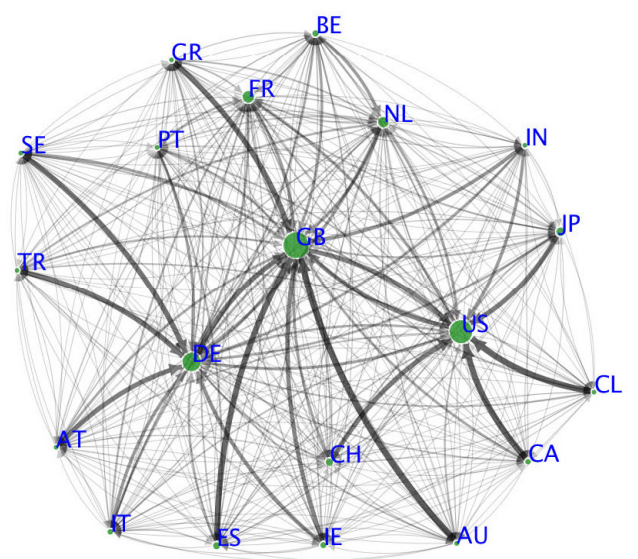

Note: The width of each edge in the networks is proportional to the components of the stochastic matrices and the size of each node is determined by the invariant distributions for the stochastic matrices.

Source: BIS Consolidated Banking Statistics (ultimate risk basis).

Figure 9: Foreign Claims (2012 Q3)

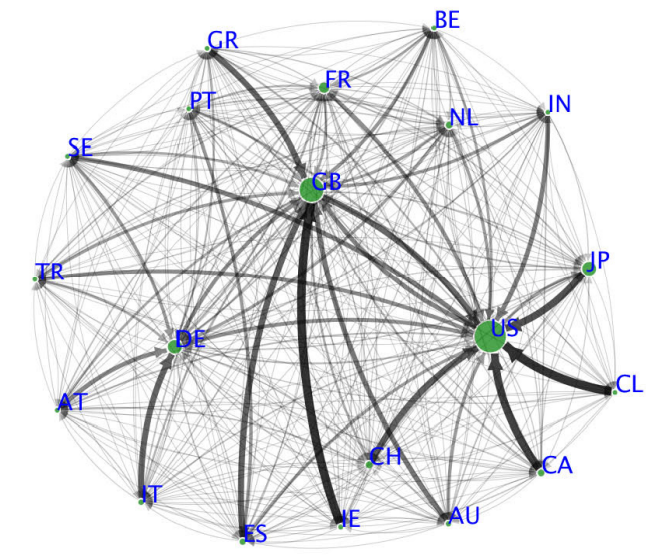

Note: See Figure 8.

Source: BIS Consolidated Banking Statistics (ultimate risk basis). 
Figure 10: Network Entropies of Foreign Claims

(2006 Q1 - 2012 Q3)
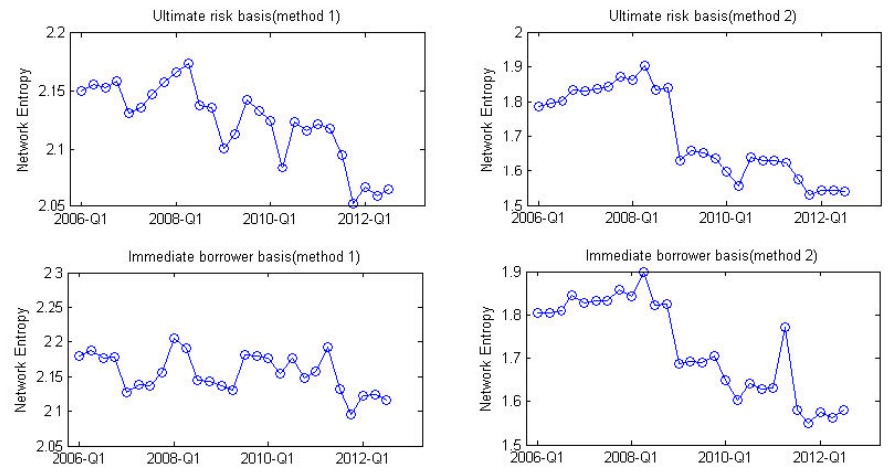

Source: BIS Consolidated Banking Statistics (foreign claims, immediate borrower basis \& ultimate risk basis).

Figure 10 shows the time variations of network entropies of foreign claims in terms of both ultimate risk basis and immediate borrower basis. The left panels of Figure 10 represent the network entropies computed by method 1 and the right panels depict the network entropies calculated by method 2. Note that the network entropy obtained from method 2 dropped sharply from the first quarter of 2009 while that from method 1 experienced moderate changes compared with method $2^{17}$. Figure 10 illustrates the point that method 2 may be better in detecting changes in network structures since it incorporates changes in the centrality of nodes whereas method 1 does not.

To see which countries are most responsible for these changes of the network entropy from method 2, let's take a closer look at the components of network entropy for the G5 countries because they are big players in global markets. Figure 11 exhibits the trends of eigenvector centralities, entropies and invariant probabilities of the G5 countries. The upper panel unveils the sizable rise of the eigenvector centrality of the US from 2009 Q1.18) It also shows the steady increase of the eigenvector centrality of Japan. In contrast, The eigenvector centralities of

17) Chinazzi et al. (2013) show that the network density of a global financial network reached its highest in 2007 by using a different dataset. From the viewpoint of early warning, the connection between unusual rise of network entropy and financial instability is an interesting future research topic.

18) Cukierman (forthcoming) points out that total US banking credit expanded at a slower pace after Lehman's downfall even though total US bank reserves experienced an unprecedent increase. 
France and Germany have decreased particularly since the 2010 European Economic Crisis. In particular, Germany has the highest eigenvector centrality in 2006 Q1 but Japan, the UK, and the US have higher eigenvector centralities in 2012 Q3 than Germany. It seems that these changes in eigenvector centrality are essential in understanding different results from the two methods since eigenvector centrality is the only distinctive feature of method 2. The middle panel displays entropies of five countries. The most severe drops have been found in the cases of Japan and the UK. Note that these two countries are more strongly connected with the US than France and Germany (see Figures 8 and 9). The observation, combined with the rising eigenvector centrality of the US, helps to understand the drivers of the remarkable drops of the entropies of Japan and the UK. In terms of invariant probabilities, the bottom panel reveals a rising tendency for the US and Japan and a descending tendency for France and Germany, which implies that more money is flowing into the US and Japan.

Figure 11: G5 Countries (2006 Q1 - 2012 Q3)
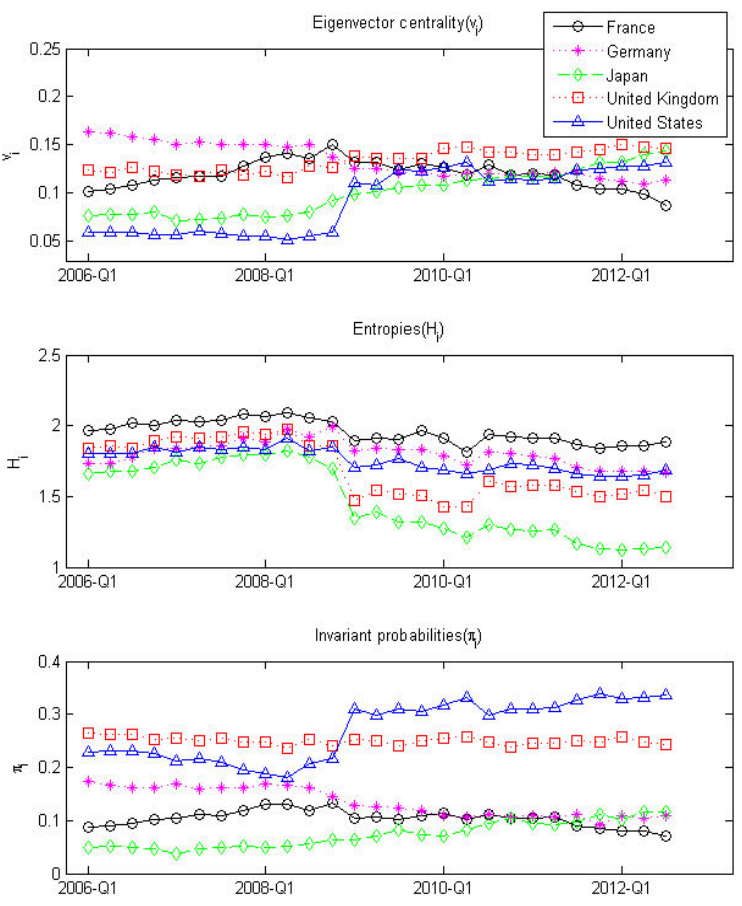

Source: BIS Consolidated Banking Statistics (ultimate risk basis). 
Table 2: Components of Network Entropy

(Foreign Claims, Ultimate Risk Basis)

\begin{tabular}{|c|c|c|c|c|c|c|c|c|c|c|c|c|}
\hline & \multicolumn{4}{|c|}{ Eigenvector centrality $\left(v_{i}\right)$} & \multicolumn{4}{|c|}{ Entropy of a node $\left(H_{i}\right)$} & \multicolumn{4}{|c|}{ Invariant distribution $\left(\pi_{i}\right)$} \\
\hline & 2006 & 2008 & 2009 & 2012 & 2006 & 2008 & 2009 & 2012 & 2006 & 2008 & 2009 & 2012 \\
\hline & Q1 & Q2 & Q1 & Q3 & Q1 & Q2 & Q1 & Q3 & Q1 & Q2 & Q1 & Q3 \\
\hline AT & 0.01 & 0.01 & 0.01 & 0.01 & 1.74 & 1.82 & 1.83 & 1.79 & 0.00 & 0.00 & 0.00 & 0.00 \\
\hline$A U$ & 0.01 & 0.01 & 0.01 & 0.02 & 1.31 & 1.33 & 1.27 & 1.43 & 0.00 & 0.01 & 0.00 & 0.01 \\
\hline $\mathrm{BE}$ & 0.06 & 0.07 & 0.04 & 0.01 & 1.87 & 1.89 & 1.89 & 1.87 & 0.02 & 0.03 & 0.01 & 0.00 \\
\hline $\mathrm{CA}$ & 0.03 & 0.02 & 0.04 & 0.07 & 1.32 & 1.35 & 0.90 & 0.80 & 0.01 & 0.01 & 0.01 & 0.03 \\
\hline $\mathrm{CH}$ & 0.12 & 0.09 & 0.09 & 0.09 & 1.59 & 1.78 & 1.38 & 1.30 & 0.03 & 0.02 & 0.02 & 0.03 \\
\hline $\mathrm{CL}$ & 0.00 & 0.00 & 0.00 & 0.00 & 1.35 & 1.65 & 0.78 & 0.58 & 0.00 & 0.00 & 0.00 & 0.00 \\
\hline $\mathrm{DE}$ & 0.16 & 0.15 & 0.13 & 0.11 & 1.73 & 1.97 & 1.83 & 1.67 & 0.17 & 0.17 & 0.13 & 0.11 \\
\hline ES & 0.05 & 0.05 & 0.05 & 0.06 & 1.41 & 1.58 & 1.29 & 1.12 & 0.03 & 0.03 & 0.03 & 0.02 \\
\hline $\mathrm{FR}$ & 0.10 & 0.14 & 0.13 & 0.09 & 1.97 & 2.09 & 1.90 & 1.88 & 0.09 & 0.13 & 0.10 & 0.07 \\
\hline GB & 0.12 & 0.12 & 0.14 & 0.15 & 1.84 & 1.97 & 1.47 & 1.50 & 0.26 & 0.24 & 0.25 & 0.24 \\
\hline $\mathrm{GR}$ & 0.00 & 0.00 & 0.00 & 0.00 & 1.70 & 1.41 & 1.54 & 1.42 & 0.00 & 0.00 & 0.00 & 0.00 \\
\hline $\mathrm{IE}$ & 0.04 & 0.04 & 0.03 & 0.01 & 1.60 & 1.66 & 1.56 & 0.59 & 0.02 & 0.02 & 0.02 & 0.00 \\
\hline $\mathbb{N}$ & 0.00 & 0.00 & 0.00 & 0.00 & 1.79 & 1.97 & 1.63 & 1.58 & 0.00 & 0.00 & 0.00 & 0.00 \\
\hline IT & 0.02 & 0.05 & 0.04 & 0.03 & 1.98 & 1.25 & 1.47 & 1.37 & 0.01 & 0.04 & 0.02 & 0.01 \\
\hline $\mathrm{JP}$ & 0.08 & 0.08 & 0.10 & 0.14 & 1.66 & 1.82 & 1.34 & 1.14 & 0.05 & 0.05 & 0.06 & 0.12 \\
\hline $\mathrm{NL}$ & 0.11 & 0.09 & 0.07 & 0.05 & 1.89 & 2.02 & 1.94 & 1.88 & 0.07 & 0.06 & 0.03 & 0.03 \\
\hline PT & 0.00 & 0.01 & 0.00 & 0.00 & 2.08 & 2.01 & 2.06 & 1.93 & 0.00 & 0.00 & 0.00 & 0.00 \\
\hline SE & 0.02 & 0.02 & 0.01 & 0.02 & 1.45 & 1.57 & 1.61 & 1.36 & 0.00 & 0.00 & 0.00 & 0.00 \\
\hline TR & 0.00 & 0.00 & 0.00 & 0.00 & 1.62 & 1.79 & 1.67 & 1.56 & 0.00 & 0.00 & 0.00 & 0.00 \\
\hline US & 0.06 & 0.05 & 0.11 & 0.13 & 1.80 & 1.91 & 1.70 & 1.68 & 0.23 & 0.18 & 0.31 & 0.34 \\
\hline
\end{tabular}

Notes: AT: Austria, AU: Australia, BE: Belgium, Ca: Canada, CH: Switzerland, CL: Chile, DE: Germany, ES: Spain, FR: France, GB: United Kingdom, GR: Greece, IE: Ireland, IN: India, IT: Italy, JP: Japan, NL: Netherlands, PT: Portugal, SE: Sweden, TR: Turkey, US: United, States

Source: BIS Consolidated Banking statistics.

Table 2 gives us a more comprehensive look at components of network entropy by providing snapshots for four periods. Table 2 includes the periods of $2008 \mathrm{Q} 2$ and 2009 Q1 for the comparison in addition to the starting and ending periods of the sample. We can see that from Table 2, besides France and Germany, the ei- 
genvector centralities of Belgium and Netherlands also declined sizably during the sample period. Regarding the entropies, it is interesting to note that only the entropies of Greece and Italy decreased between 2006 Q1 and 2008 Q2. Finally, invariant probabilities of Belgium, Austria, and Italy, in addition to France and Germany, diminished during the sample period reflecting the European debt crisis, which implies that the importance of these countries in international borrowing retreated. Overall, the analysis of the components of network entropy gives us a detailed picture about how network structures of global financial markets evolved during the financial crises.

Now, I use data on an immediate borrower basis to obtain a longer time series of network entropy. Figure 12 displays the network entropies for the period of 2000 Q1 - 2012 Q3. Again, Figure 12 compares the network entropies computed by method 1 with them calculated by method 2 . In method 2 , the drops in network entropies from 2009 are unprecedented even with longer time series. ${ }^{19)}$

Figure 12: Network Entropies (2000 Q1 - 2012 Q3)
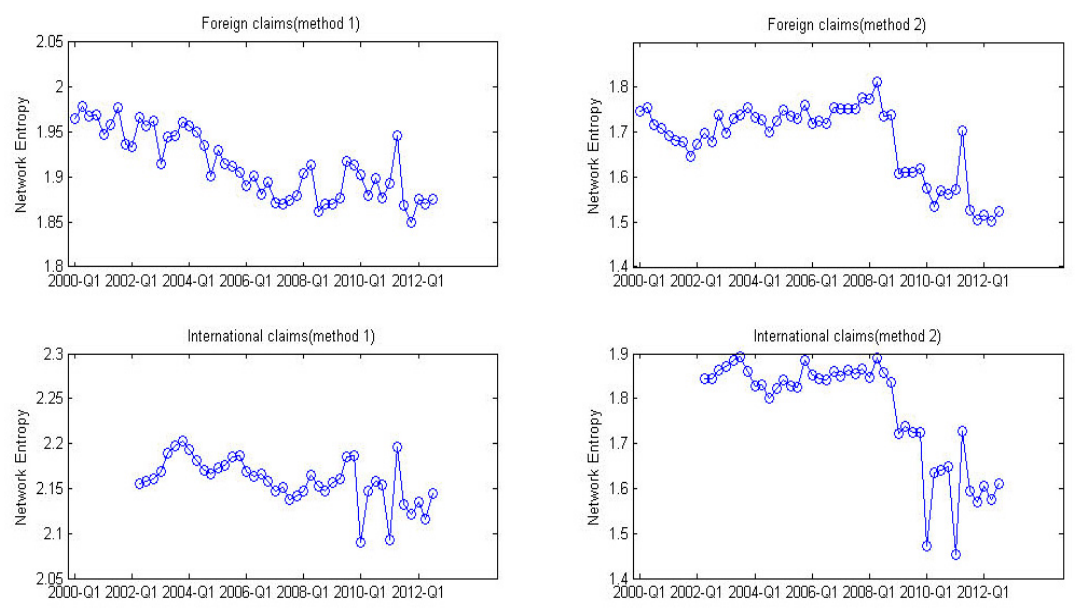

Source: BIS consolidated banking statistics (immediate borrower basis).

19) Among several entropy measures, an asymptotic distribution theory for permutationentropy has been developed (see Matilla-García and Marin (2008), for example). But, to the best of my knowledge, an asymptotic distribution theory for network entropy is still missing from the literature. 


\subsubsection{Network Entropy and SIFIs}

Demetrius and Manke (2005) propose the contribution to network entropy as a ranking principle. Figure 13 visualizes the financial network in 2012 Q3 for 26 countries. Table 3 reports the relative contributions of the countries to the network entropy computed in both methods. Big players have more weights in method 2. The result seems to reflect that method 2 is supposed to capture the amplification due to the network effect. The novel feature of the network entropy approach is the inclusion of both left-eigenvector and right-eigenvector in the computation for ranking whereas the existing literature on eigenvector centrality uses either left-eigenvector or right-eigenvector in the computation.

Table 3: Relative Contributions to Network Entropy

\begin{tabular}{|c|c|c|c|c|}
\hline Rank & \multicolumn{2}{|c|}{ method1 } & \multicolumn{2}{|c|}{ method2 } \\
\hline 1 & US & 0.28 & US & 0.36 \\
\hline 2 & GB & 0.18 & GB & 0.24 \\
\hline 3 & DE & 0.09 & DE & 0.11 \\
\hline 4 & FR & 0.08 & FR & 0.09 \\
\hline 5 & $\mathrm{NL}$ & 0.06 & $\mathrm{JP}$ & 0.08 \\
\hline 6 & $\mathrm{JP}$ & 0.05 & $\mathrm{NL}$ & 0.04 \\
\hline 7 & ES & 0.03 & $\mathrm{CH}$ & 0.02 \\
\hline 8 & $\mathrm{BR}$ & 0.02 & ES & 0.01 \\
\hline 9 & IT & 0.02 & IT & 0.01 \\
\hline 10 & IU & 0.02 & CA & 0.01 \\
\hline 11 & $\mathrm{BE}$ & 0.02 & $A U$ & 0.01 \\
\hline 12 & $\mathrm{KR}$ & 0.02 & BE & 0.00 \\
\hline 13 & $\mathrm{CH}$ & 0.02 & SE & 0.00 \\
\hline 14 & AT & 0.01 & $\mathrm{E}$ & 0.00 \\
\hline 15 & $\mathrm{IE}$ & 0.01 & $\mathrm{KR}$ & 0.00 \\
\hline 16 & SE & 0.01 & BR & 0.00 \\
\hline 17 & CA & 0.01 & DK & 0.00 \\
\hline 18 & DK & 0.01 & TW & 0.00 \\
\hline 19 & TR & 0.01 & PT & 0.00 \\
\hline 20 & $\mathrm{Fl}$ & 0.01 & AT & 0.00 \\
\hline 21 & TW & 0.01 & TR & 0.00 \\
\hline 22 & $M X$ & 0.01 & GR & 0.00 \\
\hline 23 & $\mathrm{CL}$ & 0.01 & $\mathrm{Fl}$ & 0.00 \\
\hline 24 & PT & 0.01 & $M X$ & 0.00 \\
\hline 25 & PA & 0.00 & PA & 0.00 \\
\hline 26 & GR & 0.00 & $\mathrm{CL}$ & 0.00 \\
\hline
\end{tabular}


Figure 13: Global Financial

Network (2012 Q3)

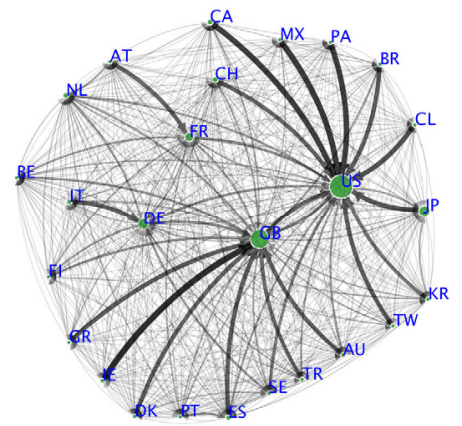

Source: BIS Consolidated Banking Statistics (immediate borrower basis).

\subsection{Periphery (non-reporting countries)}

Since lending data for non-reporting countries are not available from the BIS consolidated banking statistics, I focus on the borrowing patterns of non-reporting countries. The main question in this part is whether we can find some stylized facts about the relationship between reporting countries and non-reporting countries in terms of entropies of nodes.

\subsubsection{Counterparty Entropy}

For the purpose, I define counterparty entropy $(\mathrm{CH})$ as follows:

$$
C H_{j}=\sum_{i}\left(\frac{b_{i j}}{\sum_{h} b_{h j}}\right) H_{i}, i, h \in 20 \text { reporting countries }
$$

where $b_{i j}$ is the foreign claim of reporting country $\mathrm{i}$ on non-reporting country $\mathrm{j}$.

The counterparty entropy $\left(\mathrm{CH}_{j}\right)$ of country $\mathrm{j}$ is a weighted average of the entropies of the countries from which country $\mathrm{j}$ borrow money where weights are given by relative size of lending. So, by comparing counterparty entropies of countries, we can see which countries are more closely connected to the reporting countries with relatively high entropy.

The left panel of Figure 14 displays the time series of foreign claims on an ultimate risk basis by region. We can see that inflows into Latin and Asia have increased while Europe and Africa \& Middle East have stagnated from around 2009. 
Figure 14: Counterparty Entropies by Region

(Foreign Claims, 2006 Q1 - 2012 Q3)
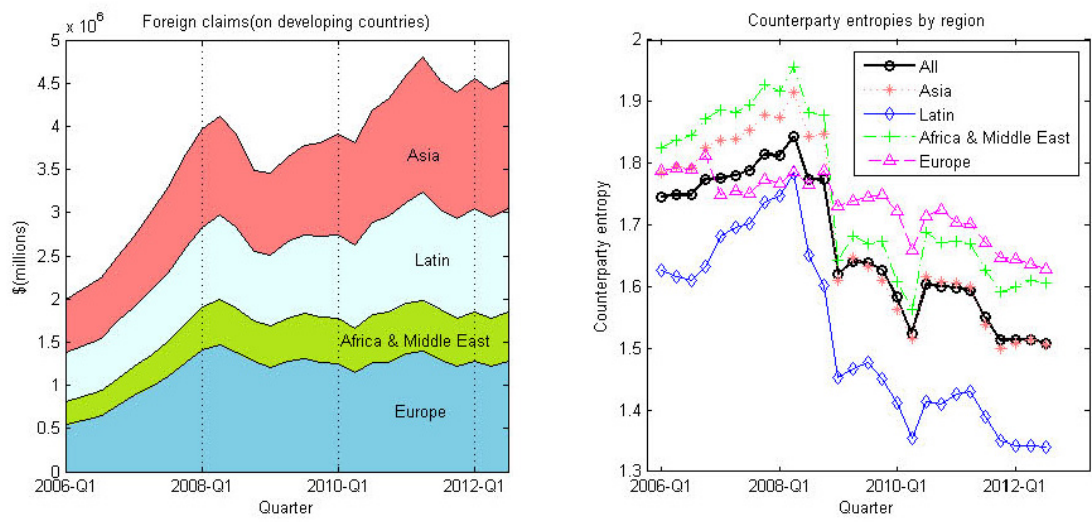

Source: BIS consolidated banking statistics (ultimate risk basis).

The right panel of Figure 14 shows regional variations of counterparty entropies. From 2009, counterparty entropies decreased reflecting the drops of entropies of reporting countries. Among the four regions, the counterparty entropy of Latin America has been lowest and dropped most significantly.

Figure 15: Sources of Borrowing
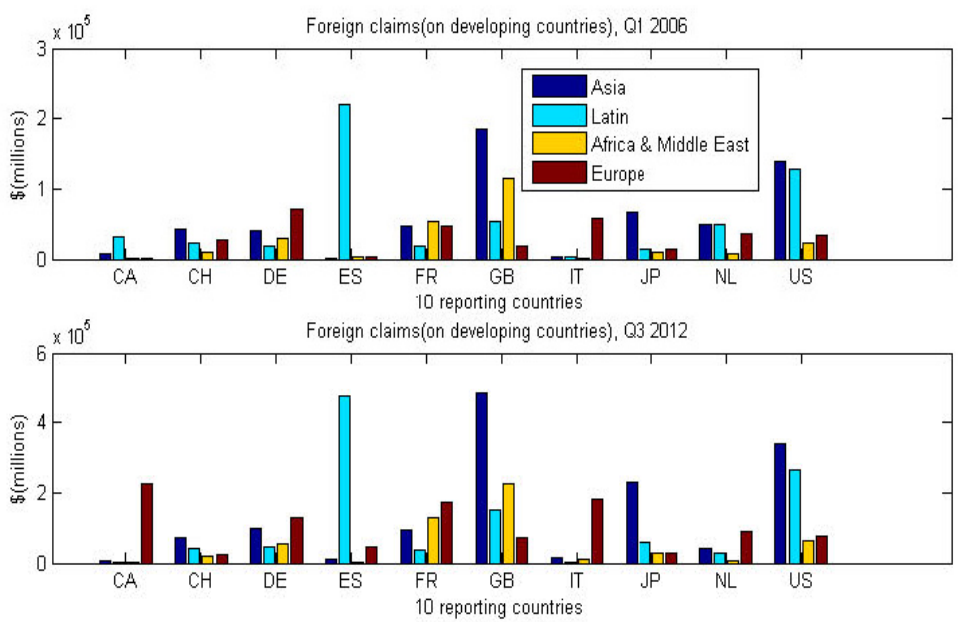

Source: BIS Consolidated Banking Statistics (ultimate risk basis). 
To grasp the regional differences, I look into the sources of funding. Figure 15 demonstrates the heterogeneity in the sources of funding across regions. The salient feature of Latin America is that its funding heavily depends on Spain. Recall that from Table 2, Spain has relatively low entropies compared with the other major reporting countries in Figure 15.

Figure 16 provides longer time series of the counterparty entropies of developing countries based on foreign claims on an ultimate risk basis. Figure 16 shows that heterogeneity in terms of counterparty entropy across four regions has increased. Particularly, the entropies of Latin America sizably declined in 2004. At that time, the entropies of Spain also fell significantly .

Figure 16: Counterparty Entropies by Region

(Foreign Claims, 2000 Q1 - 2012 Q3)
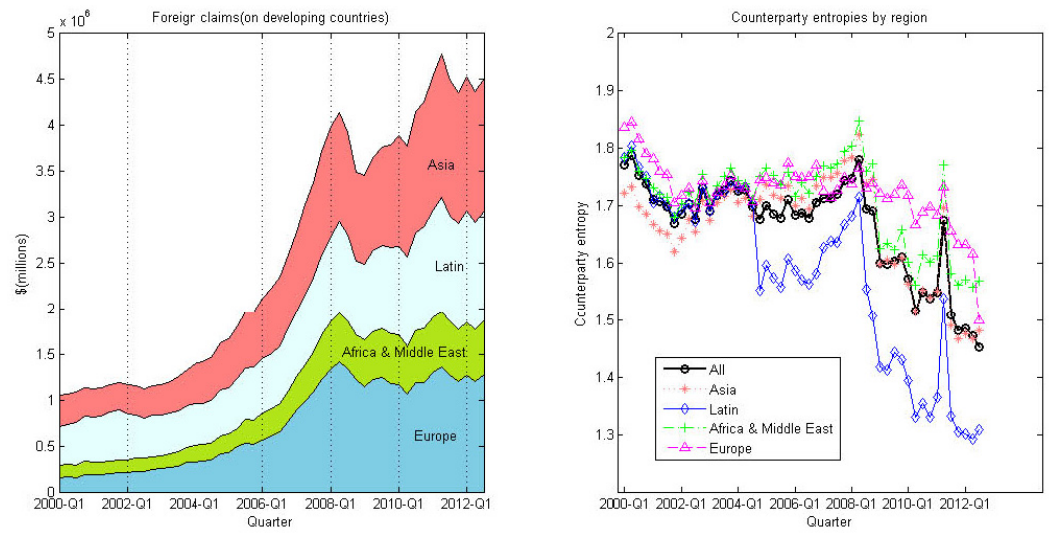

Source: BIS Consolidated Banking Statistics (Immediate borrower basis).

\subsubsection{Funding Entropy}

To quantify the diversity of funding sources of developing countries, I propose an entropy-based measure, funding entropy. Funding entropy utilizes the information about lending countries provided by eigenvector centrality obtained in Section 3.1.1. The probability distribution for funding entropy of country $\mathrm{j}$ is defined as follows:

$$
p_{j}^{f}(i)=\frac{b_{i j} v_{i}}{\sum_{k} b_{k j} v_{k}}, i \in 20 \text { reporting contries }
$$


I also define simple funding entropy of country $\mathrm{j}$ for comparison as follows:

$$
p_{j}^{s f}(i)=\frac{b_{i j}}{\sum_{k} b_{k j}}, i \in 20 \text { reporting contries }
$$

Figure 17 displays (simple) funding entropies of four regions. The most remarkable difference between the two panels of Figure 17 is the (simple) funding entropies of Latin \& Caribbean area. We can conjecture that the difference in connecting patterns may be responsible for the result. By contrast, the (simple) funding entropies of developing Europe are highest in terms of the two measures, which implies that developing Europe achieves the highest level of international diversification in funding sources.

Figure 17: Funding Entropy (2006 Q1 - 2012 Q3)
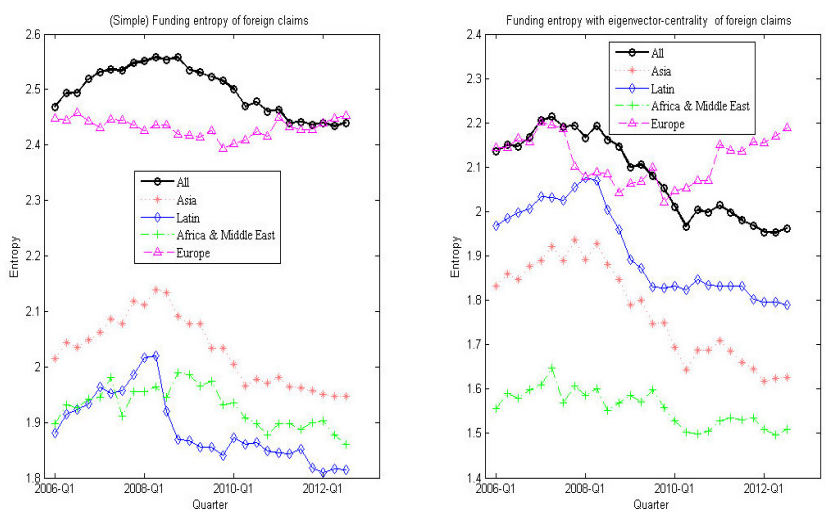

Source: BIS Consolidated Banking Statistics (ultimate risk basis).

\subsubsection{Funding Entropy and Volatility}

Portfolio diversification has been viewed as a way of reducing financial risk. To see whether funding entropy has additional information by including eigenvector centrality, I look at the correlation between volatility and (simple) funding entropy. The volatility of foreign claims on developing countries is defined as follows:

$$
\text { volatility } \equiv \frac{\operatorname{std}\left(\left|\log \left(y_{t+1}\right)-\log \left(y_{t}\right)\right|\right)}{\operatorname{mean}\left(\left|\log \left(y_{t+1}\right)-\log \left(y_{t}\right)\right|\right)}
$$

where $y_{t}$ is the total borrowing from 20 reporting countries. In other words, volatility is measured as a variational coefficient of the absolute values of logarithmic 
Figure 18: Funding Entropy and Volatility

(2006 Q1 - 2012 Q3)
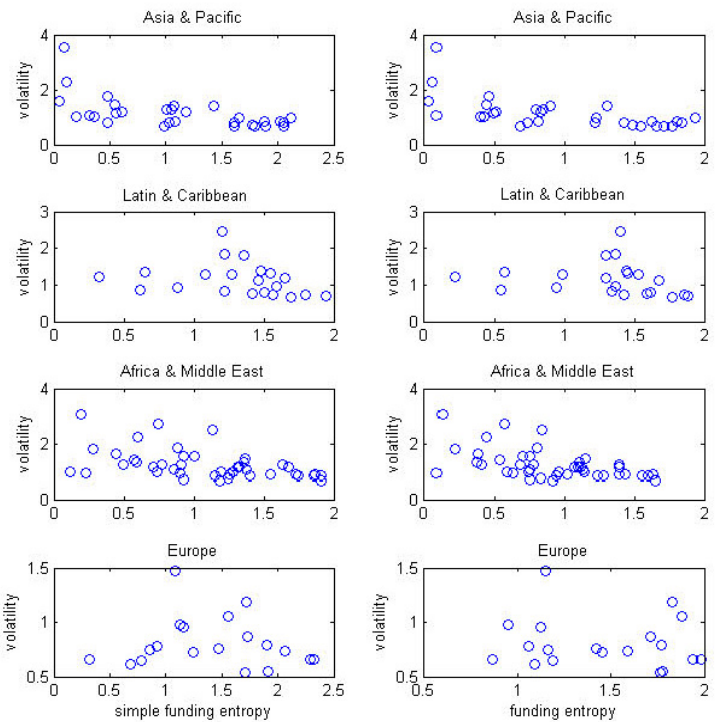

Source: BIS Consolidated Banking Statistics (ultimate risk basis).

differences. Figure 18 represents the relationships between (simple) funding entropy and volatility by region. We can see that a negative relationship between volatility and (simple) funding entropies holds for developing Asia \& Pacific and developing Africa \& Middle East.

\subsubsection{Funding Entropy and Financial Linkages}

Figure 19 displays the relationship between counterparty entropy and funding entropy by region. We can see regional heterogeneity regarding the relation. For developing Africa \& Middle East and developing Latin \& Caribbean, there exists negative relation between counterparty entropy and funding entropy. But developing Asia \& Pacific and developing Europe do not exhibit similar patterns. By contrast, a positive correlation between counterparty entropy and funding entropy is found in developing Europe. The left panels of Figure 19 depict the relationship between simple counterparty entropy and simple funding entropy, without referring to eigenvector centrality. In the case of Latin \& Caribbean, the two methods yield a very different result. Overall, these findings imply the geographical distance 
from the European area as a global financial center may be an important factor in determining network structures.

Table 4 provides detailed results on the correlation between counterparty entropy and funding entropy. As we can see from Table 4, the method with eigenvector centrality more consistently detects the correlation in the case of Latin \& Caribbean.

Table 4: The Correlation Between Counterparty Entropy and Funding Entropy

\begin{tabular}{|c|c|c|c|c|c|c|c|c|}
\hline & \multicolumn{2}{|c|}{$\begin{array}{l}\text { Asia \& } \\
\text { Pacific }\end{array}$} & \multicolumn{2}{|c|}{$\begin{array}{l}\text { Latin \& } \\
\text { Caribbean }\end{array}$} & \multicolumn{2}{|c|}{$\begin{array}{c}\text { Africa \& } \\
\text { Middle East }\end{array}$} & \multicolumn{2}{|c|}{ Europe } \\
\hline & method1 & method2 & method1 & method2 & method 1 & method2 & method1 & method2 \\
\hline 2006-Q1 & 0.12 & 0.02 & -0.35 & -0.27 & -0.37 & -0.40 & 0.28 & 0.69 \\
\hline 2006-Q2 & 0.07 & 0.05 & -0.21 & -0.59 & -0.50 & -0.40 & 0.42 & 0.57 \\
\hline 2006-Q3 & 0.14 & -0.04 & -0.66 & -0.54 & -0.37 & -0.49 & 0.43 & 0.63 \\
\hline 2006-Q4 & 0.18 & 0.05 & -0.69 & -0.60 & -0.38 & -0.42 & 0.49 & 0.72 \\
\hline 2007-Q1 & 0.05 & -0.07 & -0.72 & -0.53 & -0.50 & -0.51 & 0.46 & 0.52 \\
\hline 2007-Q2 & 0.17 & 0.01 & -0.77 & -0.62 & -0.57 & -0.58 & 0.54 & 0.62 \\
\hline 2007-Q3 & 0.18 & 0.06 & -0.77 & -0.55 & -0.52 & -0.48 & 0.44 & 0.50 \\
\hline 2007-Q4 & 0.13 & -0.04 & -0.69 & -0.65 & -0.44 & -0.57 & 0.40 & 0.68 \\
\hline 2008-Q1 & 0.17 & 0.05 & -0.67 & -0.51 & -0.16 & -0.04 & 0.43 & 0.61 \\
\hline 2008-Q2 & 0.12 & 0.02 & -0.70 & -0.67 & -0.46 & -0.50 & 0.49 & 0.73 \\
\hline 2008-Q3 & 0.08 & 0.05 & -0.17 & -0.57 & -0.41 & -0.42 & 0.49 & 0.76 \\
\hline 2008-Q4 & 0.02 & -0.03 & -0.10 & -0.53 & -0.44 & -0.49 & 0.41 & 0.64 \\
\hline 2009-Q1 & -0.04 & -0.19 & -0.13 & -0.53 & -0.49 & -0.43 & 0.43 & 0.53 \\
\hline 2009-Q2 & 0.06 & -0.10 & -0.18 & -0.59 & -0.47 & -0.47 & 0.54 & 0.55 \\
\hline 2009-Q3 & 0.02 & -0.21 & -0.13 & -0.48 & -0.56 & -0.49 & 0.46 & 0.43 \\
\hline 2009-Q4 & -0.08 & -0.29 & -0.13 & -0.52 & -0.59 & -0.54 & 0.56 & 0.45 \\
\hline 2010-Q1 & 0.06 & -0.14 & 0.42 & 0.06 & -0.41 & -0.42 & 0.46 & 0.23 \\
\hline 2010-Q2 & 0.01 & -0.21 & 0.16 & -0.33 & -0.54 & -0.53 & 0.47 & 0.22 \\
\hline 2010-Q3 & 0.15 & -0.13 & 0.16 & -0.17 & -0.01 & -0.31 & 0.61 & 0.40 \\
\hline 2010-Q4 & 0.07 & -0.24 & -0.42 & -0.70 & -0.18 & -0.37 & 0.56 & 0.43 \\
\hline 2011-Q1 & 0.10 & -0.26 & -0.34 & -0.63 & -0.00 & -0.31 & 0.63 & 0.58 \\
\hline 2011-Q2 & 0.08 & -0.23 & -0.15 & -0.54 & -0.11 & -0.24 & 0.55 & 0.56 \\
\hline 2011-Q3 & -0.01 & -0.30 & -0.37 & -0.64 & -0.41 & -0.38 & 0.54 & 0.56 \\
\hline 2011-Q4 & -0.20 & -0.38 & -0.20 & -0.60 & -0.39 & -0.22 & 0.57 & 0.56 \\
\hline 2012-Q1 & -0.02 & -0.26 & -0.07 & -0.60 & -0.54 & -0.49 & 0.62 & 0.60 \\
\hline 2012-Q2 & 0.13 & -0.11 & -0.08 & -0.56 & -0.43 & -0.44 & 0.66 & 0.60 \\
\hline 2012-Q3 & 0.14 & -0.12 & -0.22 & -0.64 & -0.48 & -0.47 & 0.66 & 0.60 \\
\hline
\end{tabular}


Figure 19: The Relationship Between Counterparty Entropy and Funding Entropy
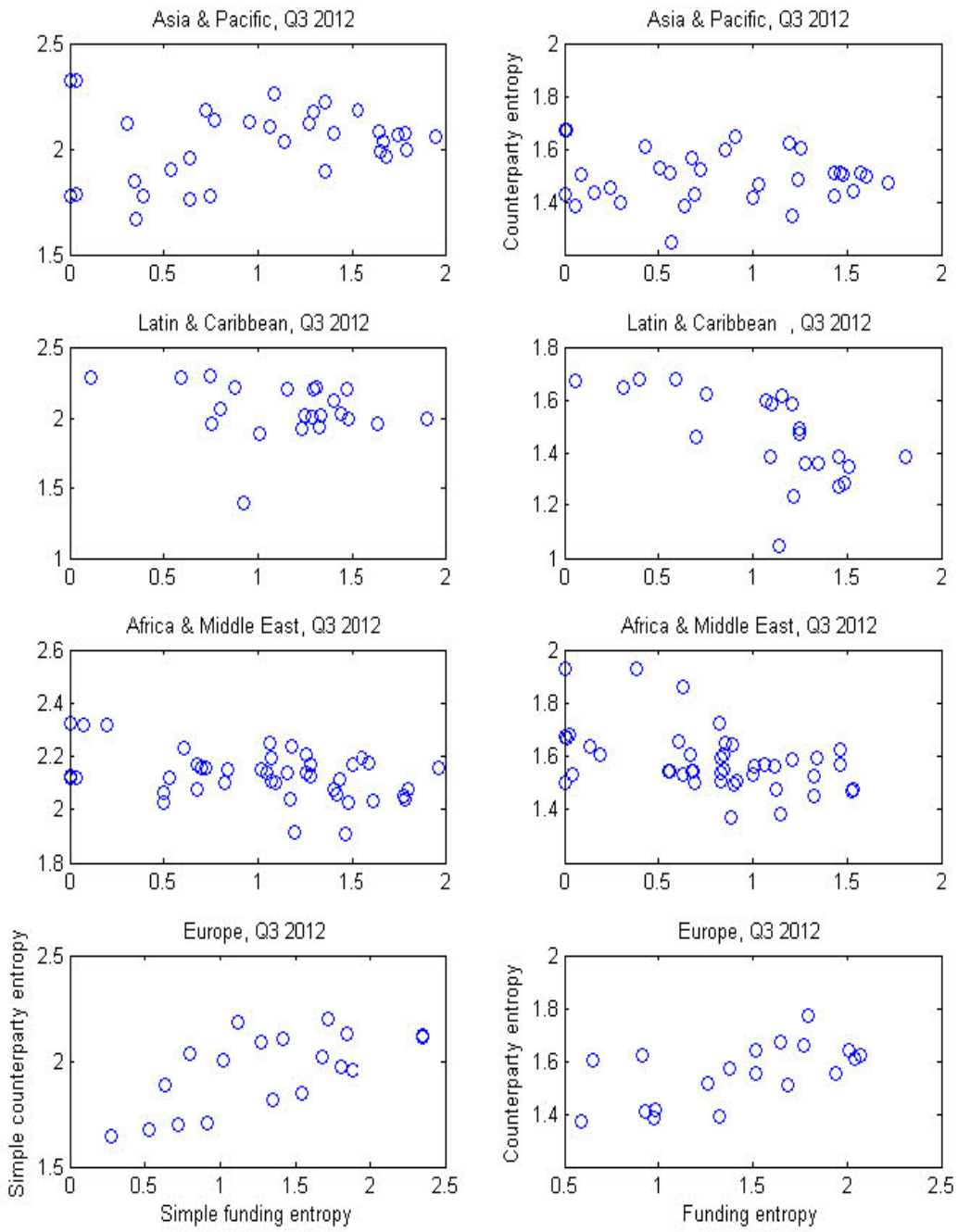

Source: BIS Consolidated Banking Statistics (ultimate risk basis). 


\section{Conclusion}

Analyzing highly connected financial networks is an important task for financial stability. Several recent papers advocate the usefulness of eigenvector centrality, a measure of nodes' centrality, in identifying important financial institutions in financial networks. This paper extends the existing approach by incorporating eigenvector centrality in measuring international diversification.

This paper proposes network entropy as a tool for measuring the diversity of highly connected financial networks. The computation of network entropy hinges on eigenvector centrality and Shannon entropy. I find some supporting evidence for the advantages of this approach in that the measures which incorporate eigenvector centrality have additional information about changes in foreign claims over other simple measures which do not include eigenvector centrality.

Two policy-related findings emerge from this research. First, regarding time variation of network entropy, international diversification of the global financial network constructed from foreign claims of international banks declines after the financial crisis of 2007-2008. Foreign claims among 20 reporting countries have become more concentrated on core countries such as US and UK from 2009. The change is more vividly captured by network entropy with an unprecedented drop of the measure. This finding illustrates the point that network entropy is a more sensitive measure for the diversity of a financial network due to the inclusion of information about financial network structures captured by eigenvector centrality. For policymakers, properly monitoring the evolving features of financial networks is essential for ensuring financial stability. It seems that network entropy has a promising potential for the purpose.

Second, on the subject of financial linkages, the results reveal sizable regional heterogeneity. In both developing Asia \&Pacific area and developing Africa \& Middle East area, there is a negative correlation between the volatility of changes in foreign claims and international diversification of funding sources measured by funding entropy. In other words, more international diversification is related with lower volatility. Especially in the case of developing Europe, however, there is no evidence for such a relation. This paper also finds interesting regional variations 
regarding the relation between international diversification of lending and international diversification of borrowing.

One limitation of this research is that I study financial networks only at the country level. In this sense, an interesting extension in this research direction would be to construct the financial networks of international banks and to see whether similar results hold. It seems that more work is required to shed some light on the salient features of highly connected networks. 


\section{<References $>$}

Acemoglu, D., A. Ozdaglar, and A. Tahbaz-Salehi (2013), "Systemic Risk and Stability in Financial Networks," NBER Working Paper 18727.

Allen, F. and D. Gale (2000), "Financial Contagion," Journal of Political Economy, Vol. 108, No.1, pp. 1-33.

Bech, M. L., J. T. Chapman, and R. J. Garratt (2010), "Which Bank Is the “Central” Bank?” Journal of Monetary Economics, Vol. 57, pp. 352-363.

BIS (2010), "Research on Global Financial Stability: The Use of BIS International Financial Statistics," CGFS Papers No 40.

BIS (2012), Guidelines to the International Consolidated Banking Statistics.

Bonacich, P. (1972), "Factoring and Weighting Approaches to Status Scores and Clique Identification," Journal of Mathematical Sociology,

Vol. 2, pp. 113-120.

Bonacich, P. (2007), "Some Unique Properties of Eigenvector Centrality," Social Networks, Vol. 29, pp. 555-564.

Caballero, R. J. and A. Simsek (2013), "Fire Sales in a Model of Complexity," Journal of Finance, Vol. 68, No. 6, pp. 2549-2587.

Castrén, O. and M. Rancan (2013), "Macro-Networks: An Application to the Euro Area Financial Accounts,” ECB Working Paper No. 1510.

Cetorelli, N. and S. Peristiani (2013), "Prestigious Stock Exchanges: A Network Analysis of International Financial Centers," Journal of Banking \& Finance, Vol. 37, pp. 1543-1551.

Chinazzi, M., G. Fagiolo, J. A. Reyes, and S. Schiavo (2013), "Post-Mortem Examination of the International Financial Network," Journal of Economic Dynamics \& Control, Vol. 37, pp. 1692-1713.

Cukierman, A. (forthcoming), "Monetary Policy and Institutions Before, During, and After the Global Financial Crisis," Journal of Financial Stability.

Degryse, H., M. A. Elahi, and M. F. Penas (2010), "Cross-Border Exposures and Financial Contagion," International Review of Finance, Vol. 10, No. 2, 209-240. 
Dehmer, M. and A. Mowshowitz (2011), "A History of Graph Entropy Measures," Information Sciences, Vol. 181, pp. 57-78.

Demetrius, L. and T. Manke (2005), "Robustness and Network Evolution-An Entropic Principle,” Physica A, Vol. 346, pp. 682-696.

Gai, P., A. Haldane, and S. Kapadia (2011), "Complexity, Concentration and Contagion,” Journal of Monetary Economics, Vol. 58, pp. 453-470.

Hale, G. (2012), "Bank Relationships, Business Cycles, and Financial Crises," Journal of International Economics, Vol. 88, No. 2, pp. 312-325.

IMF (2010), Understanding Financial Interconnectedness.

Jackson, M. O. (2008), Social and Economic Networks, Princeton University Press.

Jacquemin, A. P. and C. H. Berry (1979), "Entropy Measure of Diversification and Corporate Growth," Journal of Industrial Economics, Vol. 27, No. 4, pp. 359-369.

Koralov, L. and Y. G. Sinai (2012), Theory of Probability and Random Processes, Springer.

Lax, P. D. (2008), Linear Algebra and Its Applications, John Wiley.

Markose, S., S. Giansante, and A. R. Shaghaghi (2012), “"Too Interconnected to Fail' Financial Network of US CDS Market: Topological Fragility and Systemic Risk," Journal of Economic Behavior \& Organization, Vol. 83, pp. 627-646.

Markose, S. M. (2012), "Systemic Risk from Global Financial Derivatives: A Network Analysis of Contagion and its Mitigation with Super-Spreader Tax,” IMF Working Paper WP/12/282.

Matilla-García, M. and M. R. Marin (2008), "A Non-Parametric Independence Test Using Permuation Entropy," Journal of Econometrics, Vol. 144, pp. $13-155$.

Meyer, C. D. (2000), Matrix Analysis and Applied Linear Algebra. SIAM.

Minoiu, C. and J. A. Reyes (2013), "A Network Analysis of Global Banking: 1978-2010,” Journal of Financial Stability, Vol. 9, pp. 168-184.

Newman, M. E. J. (2011), Networks: An Introduction, Oxford University Press.

Peron, T. K. D., L. da Fontoura Costa, and F. A. Rodrigues (2012), "The 
Structure and Resilience of Financial Market Networks," Chaos, Vol. 22.

Seneta, E. (2006), Non-Negative Matrices and Markov Chains, Springer.

Shannon, C. E. (1948), "A Mathematical Theory of Communication," The Bell System Technical Journal, Vol. 27, pp. 379-423.

Shin, H. S. (2012), "Global Banking Glut and Loan Risk Premium," IMF Economic Review, Vol. 60, No. 2, pp. 155-192.

Upper, C. (2011), "Simulation Methods to Assess the Danger of Contagion in Interbank Markets," Journal of Financial Stability, Vol. 7, pp. 111-125.

Upper, C. and A. Worms (2004), "Estimating Bilateral Exposures in the German Interbank Market: Is There a Danger of Contagion?" European Economic Review, Vol. 48, pp. 827-849.

Weistroffer, C. and J. Möbert (2010), Monitoring Cross-Border Exposure: A Primer on how to Exploit the BIS Banking Statistics, Deutsche Bank Research Current Issues.

Yellen, J. L. (2013), "Interconnectedness and Systemic Risk: Lessons from the Financial Crisis and Policy Implications," Speech delivered at the American Economic Association/American Finance Association Joint Luncheon, San Diego, California.

Zhou, R., R. Cai, and G. Tong (2013), "Applications of Entropy in Finance: A Review," Entropy, Vol. 15, pp. 4909-4931. 


\section{<Abstract in Korean>}

이대엽*

본 연구에서는 네트워크 엔트로피 (network entropy) 지표를 이용하여 주요국 간 글로벌 금융 네트워크의 특성을 다각화 정도의 측면에서 측정하고 시기별 변화를 살펴보는 한편, 주요국과 신흥국 간의 금융연계 패턴을 차입원천의 다각화 (funding entropy) 측면에서 분석하였다.

고유벡터 중심성 (eigenvector centrality)과 Shannon 엔트로피에 기초해 구한 네트워크 엔트로피 지표를 글로벌 은행들의 대외자산 (foreign claims)에 바탕한 글로벌 금융네트워크에 적용한 본 연구의 주요 연구결과는 다음과 같다. 첫째, 네트워크 엔트로피 지표의 시기별 변화를 살펴보면, 20 개 주요 국가들의 대외자산이 2009년 이후 미국과 영국 등의 핵심 국가들에 보다 집중된 것으로 나타나는 등 글로벌 금융네트워크의 국제적 다각화 (international diversification) 정도가 2007-08년 금융위기 이후 약화된 것으로 나타났다. 이러한 변화는 본고에서 제안된 네트워크 엔트로피 측정치의 큰 폭의 하락에서 잘 드러난다. 본고의 발견은 네트워크 엔트로피 지표가 고유벡터 중심성 (eigenvector centrality)으로 포착되는 금융네트워크 구조에 대한 정보를 포함함으로써, 금융네트워크 다각화 측정을 위한 보다 민감한 (acute) 지표가 될 수 있다는 점을 잘 보여준다.

둘째, 차입원천의 다각화와 차입 변동성간 상관관계를 살펴본 결과, 지역별로 차이가 있는 것으로 나타났다. '아시아와 환태평양 지역' 및 '아프리카와 중동 지역' 등 개발도상국의 경우 차입 엔트로피 (funding entropy) 지표와 차입 변동성 간에 음의 상관관계가 존재하여 국제적 다각화의 진전이 변동성 감소와 관련되는 것으로 분석된 반면, 유럽지역 개발도상국의 경우 이러한 관계가 뚜렷하지 않은 것으로 나타났다.

* 한국은행 경제연구원 국제경제연구실 전문연구원

이 연구내용은 집필자의 개인의견이며 한국은행의 공식견해와 무관합니다. 따라서 본 논문의 내용을 보도 하거나 인용할 경우에는 집필자명을 반드시 명시하여 주시기 바랍니다. 